\title{
A 12-hour comprehensive nutrition care benefits blood glucose level and weight gain and improves outcomes in pregnant women with gestational diabetes mellitus
}

\author{
Kun Yuan ${ }^{1}$, Haoyuan Wang ${ }^{2}$, Yujia Chen ${ }^{2}$, Sijie $\mathrm{Li}^{2}$, Qiang Wang ${ }^{3}$, Yanmin $\mathrm{Cao}^{4}$, Shuqing Gao ${ }^{5}$, \\ Xiaoli $\mathrm{Xu}^{6}$, Qi Xie \\ ${ }^{1}$ Nursing Department, The Fourth Hospital of Shijiazhuang, Shijiazhuang 050011, China; ${ }^{2}$ School of Basic Medical Sciences, Hebei Medical \\ University, Shijiazhuang 050017, China; ${ }^{3}$ Department of Thoracic Surgery, The First Hospital of Hebei Medical University, Shijiazhuang 050000, \\ China; ${ }^{4}$ Emergency Department, The Fourth Hospital of Shijiazhuang, Shijiazhuang 050011, China; ${ }^{5}$ Department of Nutrition, ${ }^{6}$ Medical Record \\ Department, The Fourth Hospital of Hebei Medical University, Shijiazhuang 050011, China \\ Contributions: (I) Conception and design: K Yuan, Q Xie; (II) Administrative support: S Gao, Q Xie; (III) Provision of study materials or patients: Q \\ Wang, X Xu; (IV) Collection and assembly of data: K Yuan; (V) Data analysis and interpretation: H Wang, Y Chen, Y Cao, Q Xie; (VI) Manuscript \\ writing: All authors; (VII) Final approval of manuscript: All authors. \\ Correspondence to: Qi Xie, MS. Department of Nutrition, The Fourth Hospital of Hebei Medical University, Shijiazhuang 050011, China. Emai: \\ w1420174542@126.com.
}

Background: Gestational diabetes mellitus (GDM) is associated with adverse outcomes and neonatal complications. Its prevalence has been rapidly increasing over the last decade; it is estimated that one in six pregnant women are diagnosed with GDM. Thus, an effective management approach is necessary for women with GDM. This study investigated the effect of a 12-h comprehensive nutrition care (12h-HNC) on the metabolism and outcomes of pregnant women with GDM and neonatal birth weight and hypoglycemia.

Methods: The study included 312 pregnant women with GDM at 24-28 weeks of gestation who were treated in our department from January 2014 to December 2016. They were randomly assigned to receive a $12 \mathrm{~h}-\mathrm{HNC}(12 \mathrm{~h}-\mathrm{HNC}$ group, $\mathrm{n}=158$ ) or traditional one-time nutrition guidance (control group, $\mathrm{n}=154$ ). Maternal blood glucose levels and weight gain, as well as maternal and neonatal outcomes were evaluated and compared between the groups.

Results: Compared to those in the control group, patients in the $12 \mathrm{~h}-\mathrm{HNC}$ group had significantly lower 2-h postprandial glucose levels $(\mathrm{P}<0.05)$, lower average weight increase $(\mathrm{P}<0.05)$, and better outcomes $(\mathrm{P}<0.05)$. Neonatal birth weight and incidence of macrosomia were significantly lower in the $12 \mathrm{~h}-\mathrm{HNC}$ group. The incidence of cesarean section was similar in the two groups $(\mathrm{P}>0.05)$.

Conclusions: The 12h-HNC enabled better blood glucose and weight increase control, improving both maternal and neonatal outcomes in women with GDM. This comprehensive nutrition intervention may achieve favorable effects in clinical practice.

Keywords: Gestational diabetes mellitus (GDM); 12-h comprehensive nutrition care (12h-HNC); pregnancy outcome; neonatal birth weight

Submitted Jul 24, 2019. Accepted for publication Feb 09, 2020.

doi: 10.21037/apm.2020.03.16

View this article at: http://dx.doi.org/10.21037/apm.2020.03.16 


\section{Introduction}

Gestational diabetes mellitus (GDM) is defined as any degree of glucose intolerance with onset or first recognition during pregnancy $(1,2)$. In recent years, changes in lifestyle, unhealthy dietary behaviors, insufficient activity, and later childbearing have contributed to the increased incidence of GDM, which was reported to be up to $9.6 \%$ (3). GDM is associated with considerable risks to both the mother and the developing fetus $(4,5)$. Previous studies have shown that poor blood glucose level control is associated with increased risk of abortion, preterm labor, gestational hypertension, and infection $(6,7)$. Furthermore, high blood glucose levels in the gestation period increase the incidence of negative fetal and neonatal outcomes, such as macrosomia, deformity, and neonatal asphyxia (8-10). In addition, longterm clinical follow-up studies have indicated that up to $50 \%$ of women with GDM may develop diabetes over $20-30$ years after pregnancy $(11,12)$. Due to its gravity and dramatically increasing incidence, GDM is considered one of the most urgent health challenges of this century (13-15). At present, there is no effective approach for the treatment of GDM. Hence, a new intervention is urgently needed.

Currently, medical nutrition therapy (MNT) is the most common method to address the dietary requirements of women with GDM $(16,17)$. However, MNT has obvious shortcomings, including the lack of follow-ups $(18,19)$. The 12-h comprehensive nutrition care (12h-HNC) is a newly developed approach in the treatment of GDM that was established at The First Hospital of Beijing. It consists of nutrition recipes, postprandial exercise, health education, and regular frequent follow-ups and is considered a new intervention to replace MNT. However, the efficacy of the $12 \mathrm{~h}-\mathrm{HNC}$ in improving the pregnancy outcomes and postpartum metabolism of women with GDM remains unclear.

In this study, we explored the effects of the $12 \mathrm{~h}-\mathrm{HNC}$ in patients with GDM with the aim to establish a more rational and effective prenatal care model.

\section{Methods}

\section{Study design, participants, and definitions}

Pregnant women with GDM at 24-28 weeks of gestation treated at The Fourth Hospital of Shijiazhuang from January 2014 to December 2016 were recruited. GDM was diagnosed as the presence of at least one of the following three findings in the 75-g oral glucose tolerance test: fasting plasma glucose $(\mathrm{FPG})>5.1 \mathrm{mmol} / \mathrm{L}$, postprandial blood glucose at 1 hour (1h-PBG) $>10.0 \mathrm{mmol} / \mathrm{L}$, and/or postprandial blood glucose at 2 hours $(2 \mathrm{~h}-\mathrm{PBG})>8.5 \mathrm{mmol} / \mathrm{L}$. Patients with acute complications due to preexisting diabetes were excluded from the study. All patients were provided with written informed consent.

\section{Interventions}

Patients were randomly assigned to a $12 \mathrm{~h}-\mathrm{HNC}$ group $(n=158)$ or a control group $(n=154)$. Those in the control group received traditional one-time nutrition guidance. For the $12 \mathrm{~h}-\mathrm{HNC}$ group, patients were kept in our department from 7:00 a.m. to 7:30 p.m., accompanied by one dietitian and one nurse. The $12 \mathrm{~h}-\mathrm{HNC}$ included nutritious meals for diabetic patients ( 3 meals and 2 snacks), postprandial exercise with guidance, and nutrition health education for diabetics. The specific process is shown in Figures 1 and 2. Appropriate nutrition recipes not only provide adequate calories and nutrition for pregnant women, but also prevent postprandial hyperglycemia and starvation ketosis. Accordingly, we calculated the total calories needed in a day for each patient and tailored the nutrition recipe to the patients' individual needs (Table 1). The ratios of all nutrients are shown in Table 2. Patients received education in terms of nutrition and health related to diabetes, including relevant GDM knowledge, guidance on blood glucose monitoring, exercise guidance, and relevant nutrition knowledge (such as food exchange and calorie calculation). At the end of the day, the medical staff created a communication group on a social application, WeChat, and patients were followed up regularly. After the intervention, we communicated with the patients and solved their problems in the conversation group every night and regularly provided them with more knowledge on health. Simultaneously, we inquired about their glucose monitoring, exercise, diet, and weight control.

\section{Outcome measurement}

We recommended that patients monitor all-day blood glucose levels at least once per week. The patients' weight increase, FPG, and 2h-PBG were recorded before delivery. After delivery, relevant patient data were obtained from the hospital electronic medical records, including pregnancy outcomes, neonatal birth weight, and incidence of neonatal 


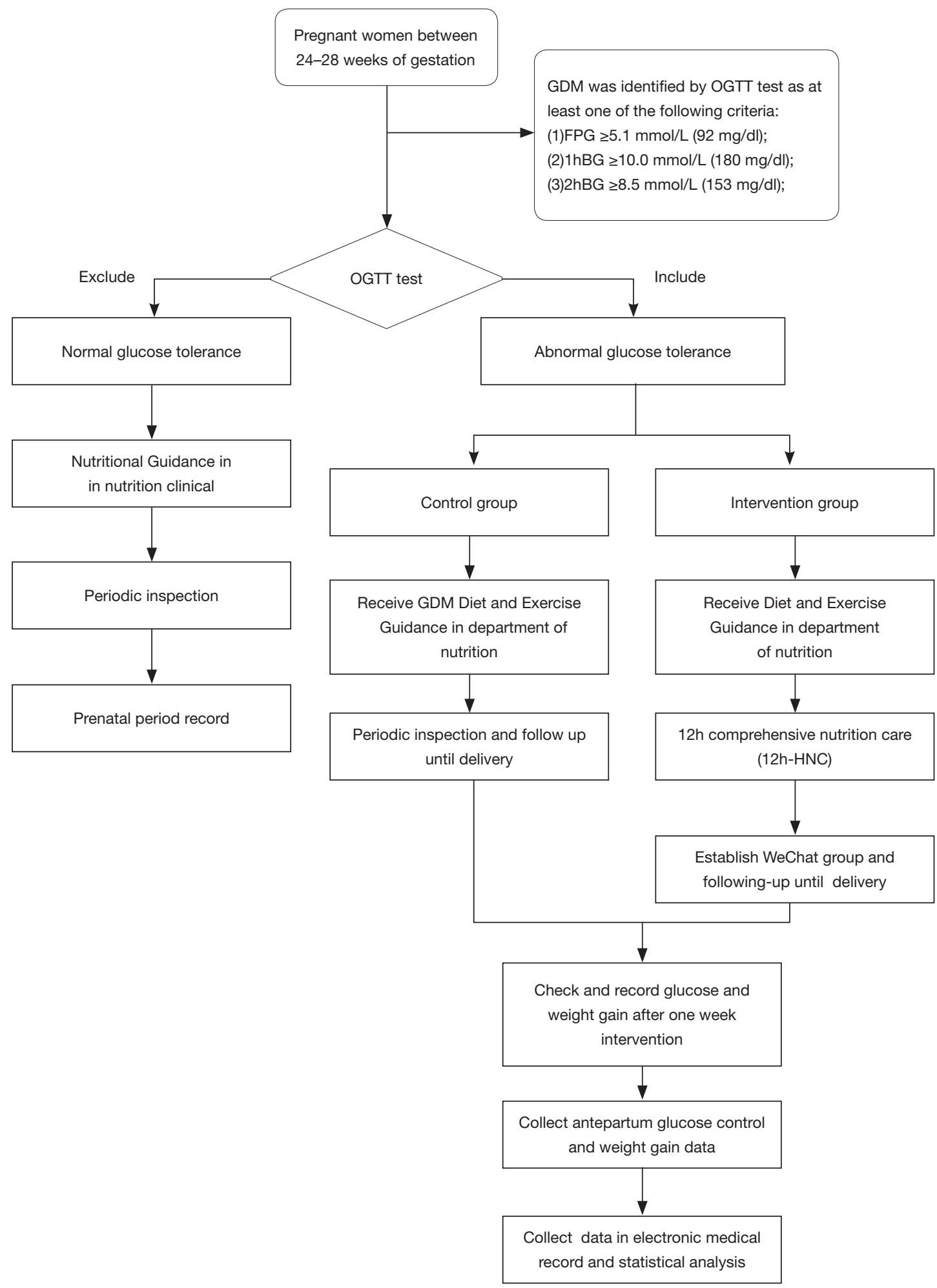

Figure 1 Study flow. Pregnant women underwent oral glucose tolerance test. Those who were diagnosed with gestational diabetes mellitus (GDM) were randomly assigned to an intervention group or a control group. The former received a 12-h comprehensive nutrition intervention, and the latter received routine nutrition guidance. At the end, the data were collected and analyzed. 


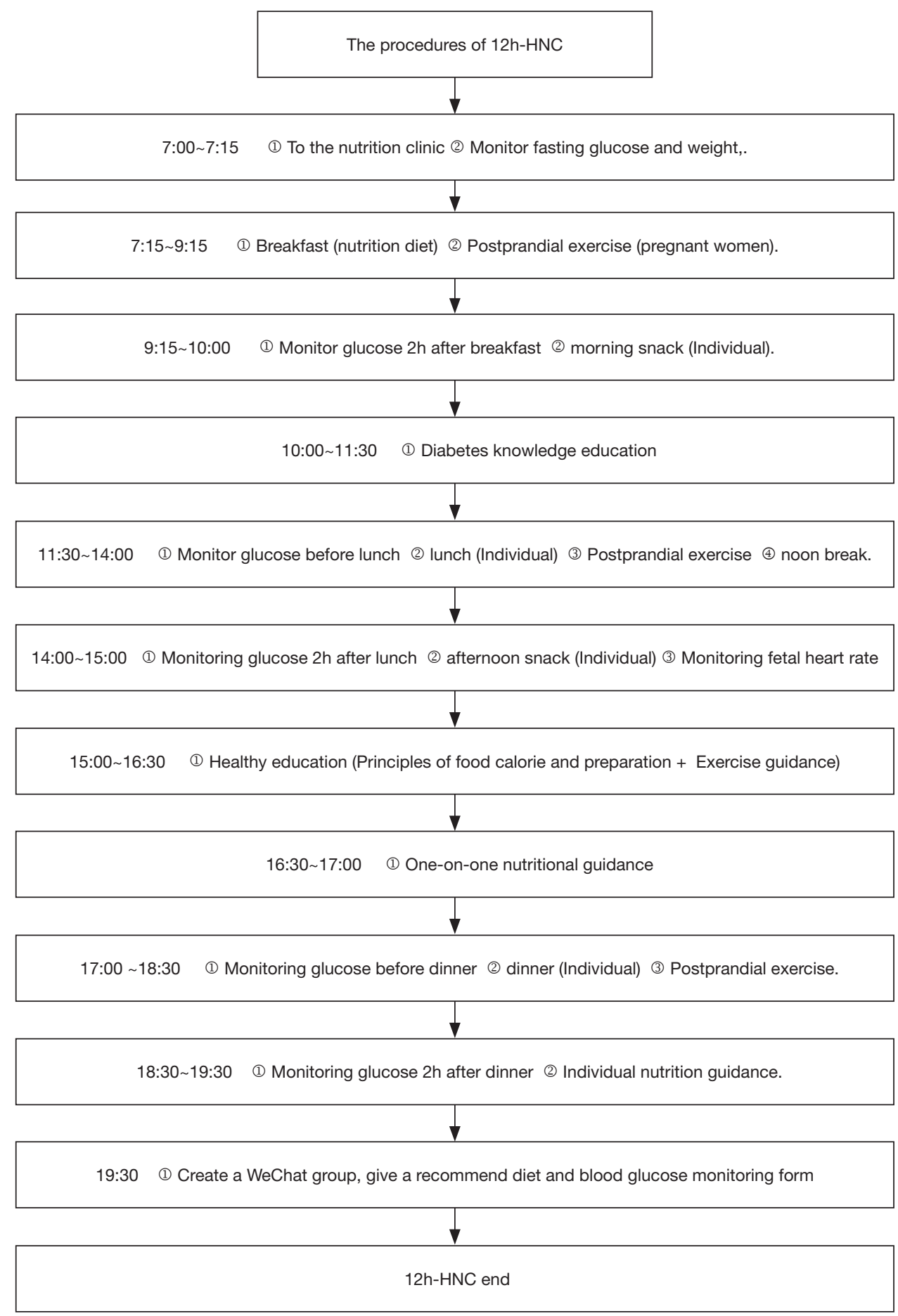

Figure 2 The process of the 12-h comprehensive nutrition intervention. It lasted from 7:00 a.m. to 07:30 p.m. and included recommended diet, exercise guidance, and health education, tailored per the patients' individual needs. 
Table 1 The nutrition diet and nutrient recommendation in 12-hour comprehensive intervention

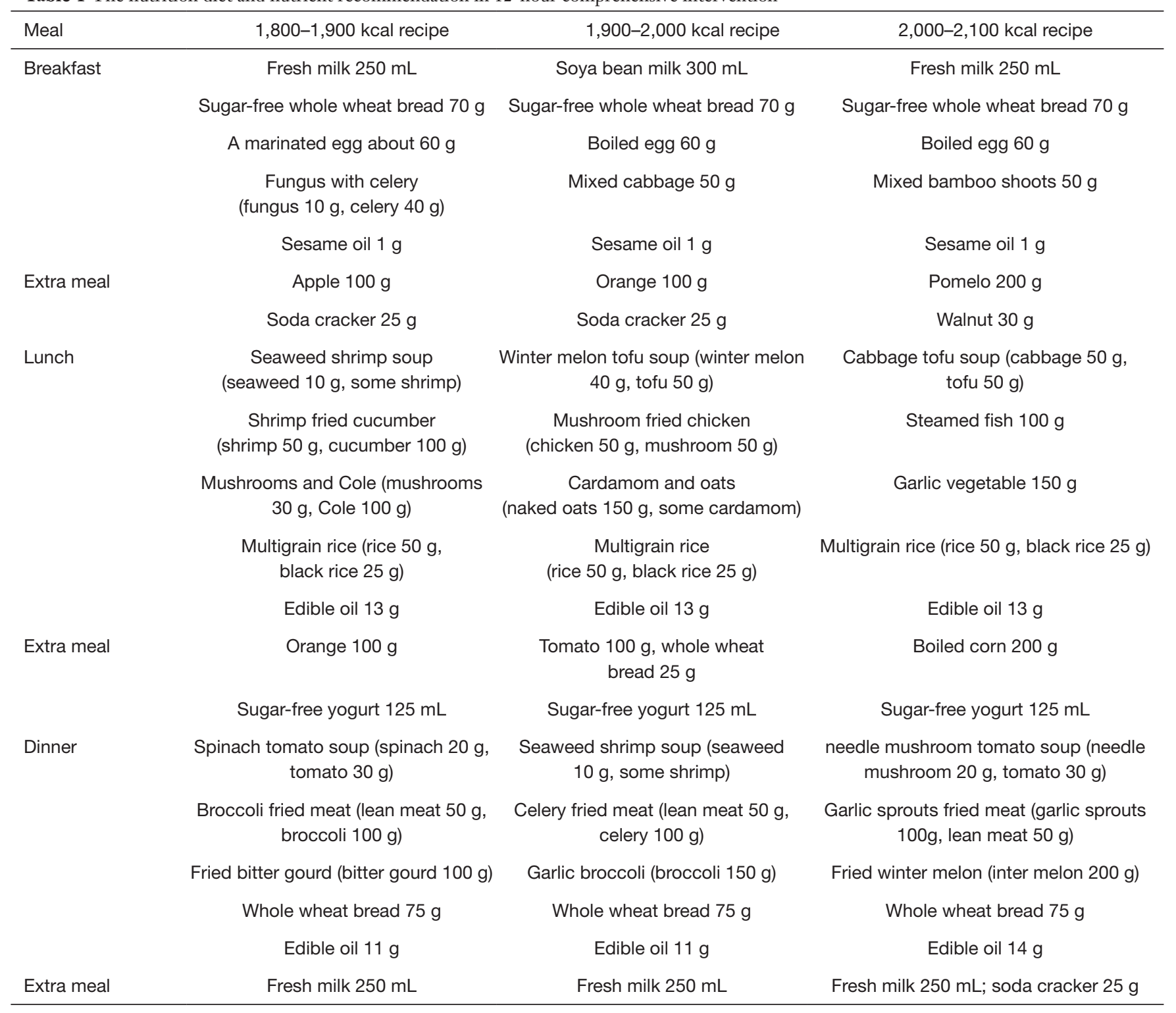

Table 2 Ratio of nutrition

\begin{tabular}{lccc}
\hline Nutrient & $1,800-1,900 \mathrm{kcal}$, nutrient ratio [g (\%)] & $1,900-2,000 \mathrm{kcal}$, nutrient ratio [g (\%)] & 2,000-2,100 kcal, nutrient ratio [g (\%)] \\
\hline Protein & $90.3(20.0)$ & $95.5(20.1)$ & $102.3(20.5)$ \\
Lipid & $51.7(25.5)$ & $55.9(26.5)$ & $65.6(29.5)$ \\
Carbohydrate & $249.6(54.7)$ & $253.7(53.4)$ & $250.1(50.0)$ \\
Dietary fiber & 23.4 & 25.1 & 35 \\
\hline
\end{tabular}


Table 3 The baseline characteristics of pregnant women with GDM in two groups

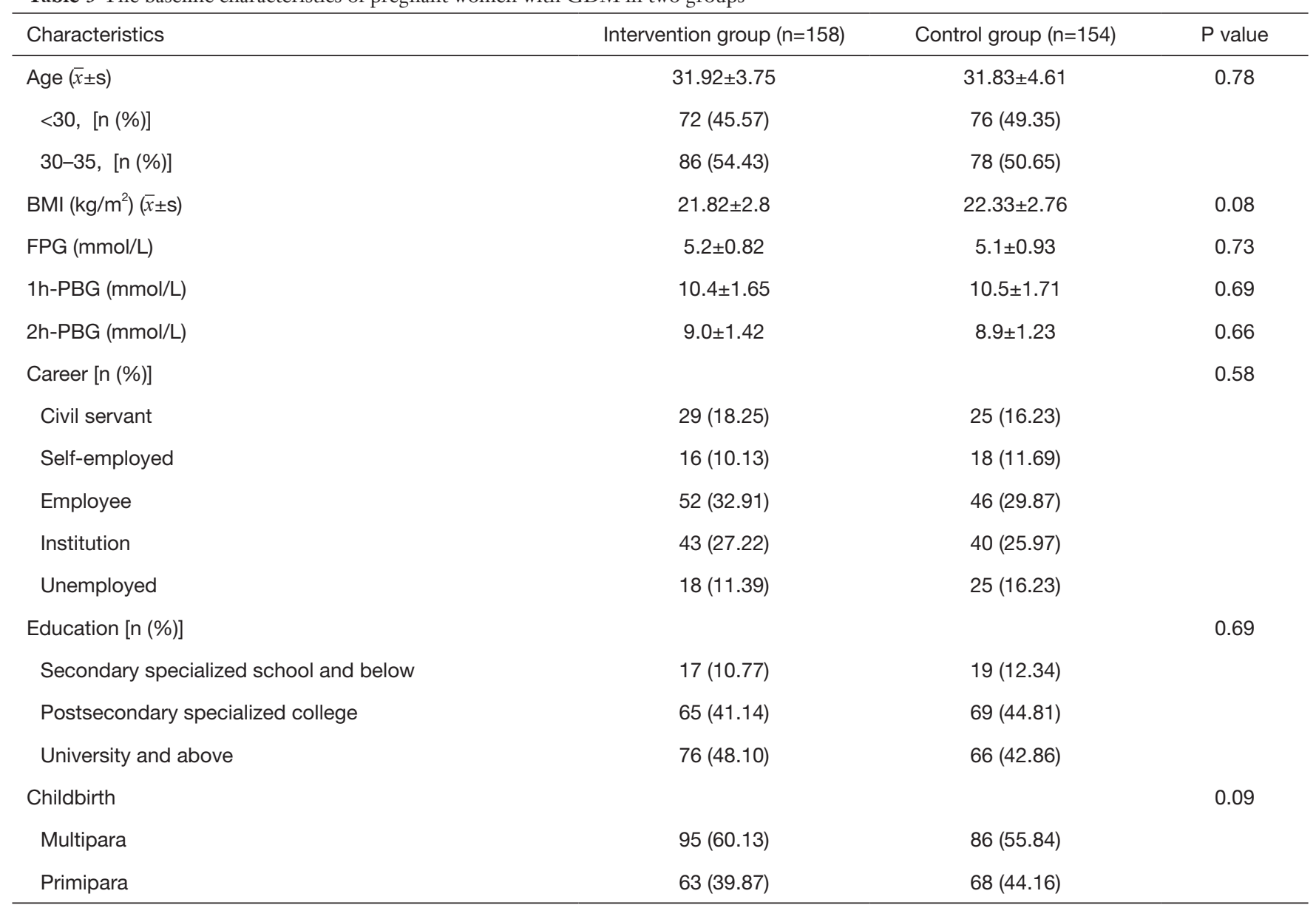

hypoglycemia.

\section{Statistical analysis}

Data are expressed as mean \pm standard deviation or $n$ (\%). Intergroup differences were analyzed using a twotailed Student's $t$-test or $\chi^{2}$ test. $\mathrm{P}$ values of $<0.05$ were considered statistically significant. All statistical analyses were performed with the SPSS statistical software package version 21.0.

\section{Results}

A total of 312 pregnant women with GDM were enrolled in this study, with 154 in the control group and 158 in the $12 \mathrm{~h}-\mathrm{HNC}$ group. The baseline characteristics of patients in both groups are shown in Table 3. In the comparative analysis, patients in the $12 \mathrm{~h}-\mathrm{HNC}$ group had significantly lower 2h-PBGlevels (Figure 3, $\mathrm{P}<0.05$ ) and average weight increase (Figure 4, $\mathrm{P}<0.05$ ) than those in the control group.

In the comparison of the pregnancy outcomes between the two groups, patients in the $12 \mathrm{~h}-\mathrm{HNC}$ group had a significantly lower incidence of gestational hypertension, premature rupture of membranes, and preterm labor (Figure 5, $\mathrm{P}<0.05)$. However, there was no significant difference in the incidence of cesarean section $(\mathrm{P}>0.05)$. Neonatal birth weight and incidence of macrosomia were significantly lower in the $12 \mathrm{~h}-\mathrm{HNC}$ group than in the control group (Figure 6, $\mathrm{P}<0.05$ ).

\section{Discussion}

The prevalence of GDM has been rapidly increasing in recent years worldwide and has increased significantly over the past two decades in China (20). GDM is associated with increased incidence of adverse maternal, fetal, and neonatal 
A

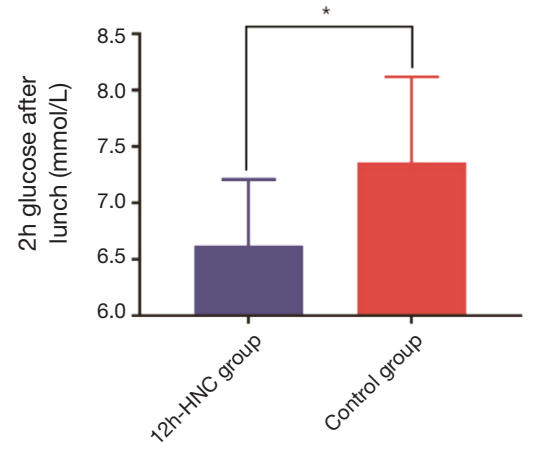

B

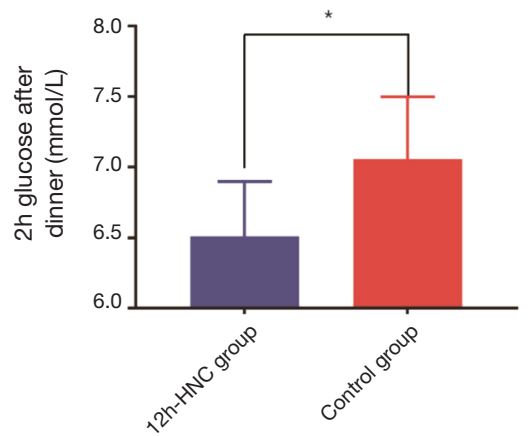

Figure 3 Postprandial blood glucose levels. The 2-h glucose levels after lunch (A) and dinner (B) were significantly lower in the intervention group. ${ }^{*}, \mathrm{P}<0.05$.

outcomes and increased risk of subsequent diabetes mellitus for mothers $(21,22)$. Women with GDM have high blood glucose levels and abnormal glucose tolerance. It has been widely demonstrated that hypoglycemic therapy in GDM can improve pregnancy outcomes (23). However, the side effect of hypoglycemic agents on pregnant women remains unknown, and many patients refuse to receive hypoglycemic therapy. Furthermore, maintaining a healthy weight is also important. It has been reported that women with obesity are more likely to develop GDM. Liu et al. suggested that high rates of gestational weight gain, particular during early pregnancy, might increase a woman's risk of GDM (24). Logan et al. showed that women with GDM were at higher risk of later metabolic disease (25). Black et al. demonstrated that obesity could lead to adverse outcomes regardless of the presence of GDM during pregnancy (26). Therefore, it is equally important to control both the weight increase and the blood glucose levels in women with GDM.

Traditional MNT is the most commonly used method for controlling blood glucose levels in women with GDM (27). However, its efficacy is unsatisfactory because of the lack of follow-ups. In this study, we proposed a new intervention, called the $12 \mathrm{~h}-\mathrm{HNC}$, to enhance blood glucose level
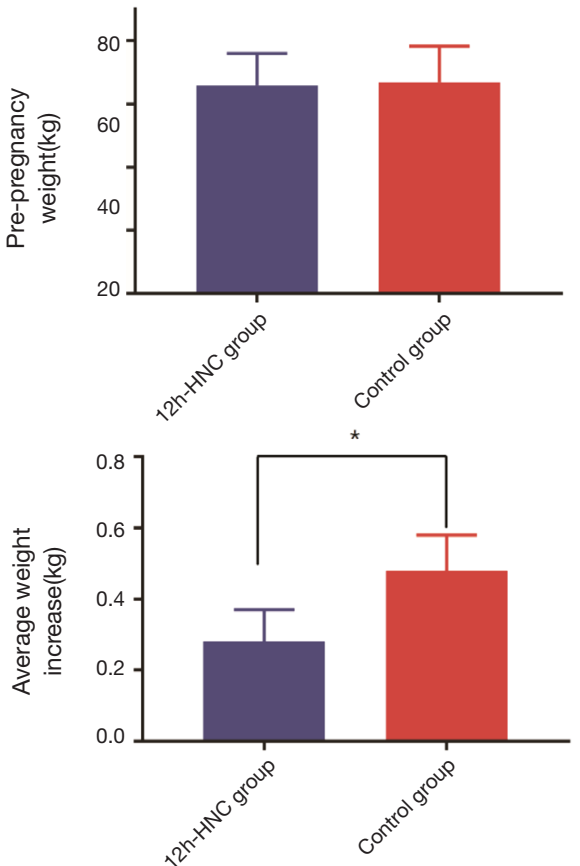

Figure 4 Weight gain comparison. The intervention group had lower average weight increase than the control group. *, $\mathrm{P}<0.05$.

control in pregnant women with GDM. The $12 \mathrm{~h}-\mathrm{HNC}$ consists of nutrition recipes, postprandial exercise, health education, and regular follow-ups. During the $12 \mathrm{~h}-\mathrm{HNC}$, patients learned to formulate a reasonable diet themselves and exercise in moderation, which helped them to control their blood glucose levels and weight increase. Patients who received $12 \mathrm{~h}-\mathrm{HNC}$ regularly monitored their blood glucose levels themselves. Moreover, the proper diet and exercise lowered the weight increase in these patients. Our continuous follow-up was an important measure to improve patient compliance, which made up for the shortcomings of MNT.

Comparison of patients' outcomes showed that the $12 \mathrm{~h}-\mathrm{HNC}$ could reduce the risk of gestational hypertension, premature rupture of membranes, and preterm labor. Furthermore, consistent with the findings of previous studies (28), our results showed that the $12 \mathrm{~h}-\mathrm{HNC}$ had a positive effect on controlling neonatal birth weight and incidence of macrosomia. This intervention could lower the blood glucose levels, which helped to lower newborns' weight. We found no significant difference between the two groups in the incidence of cesarean section, which was inconsistent with our previous findings. We speculate that this discrepancy can be attributed to the increasing trend 

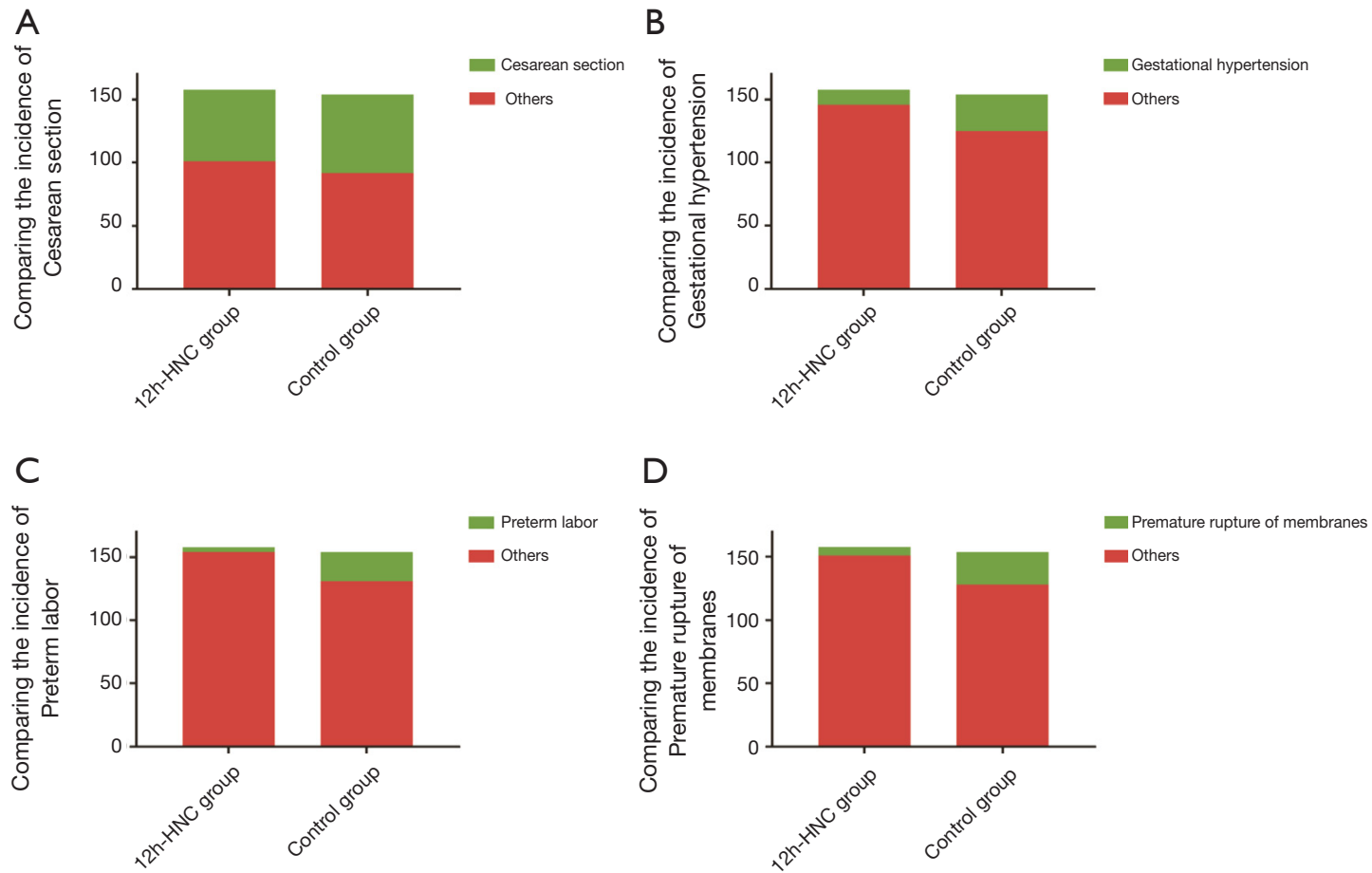

Figure 5 Maternal outcome comparison. (A) No difference was found between the two groups in the incidence of cesarean section. The intervention group had better outcomes regarding (B) gestational hypertension, (C) preterm labor, and (D) premature rupture of membranes.
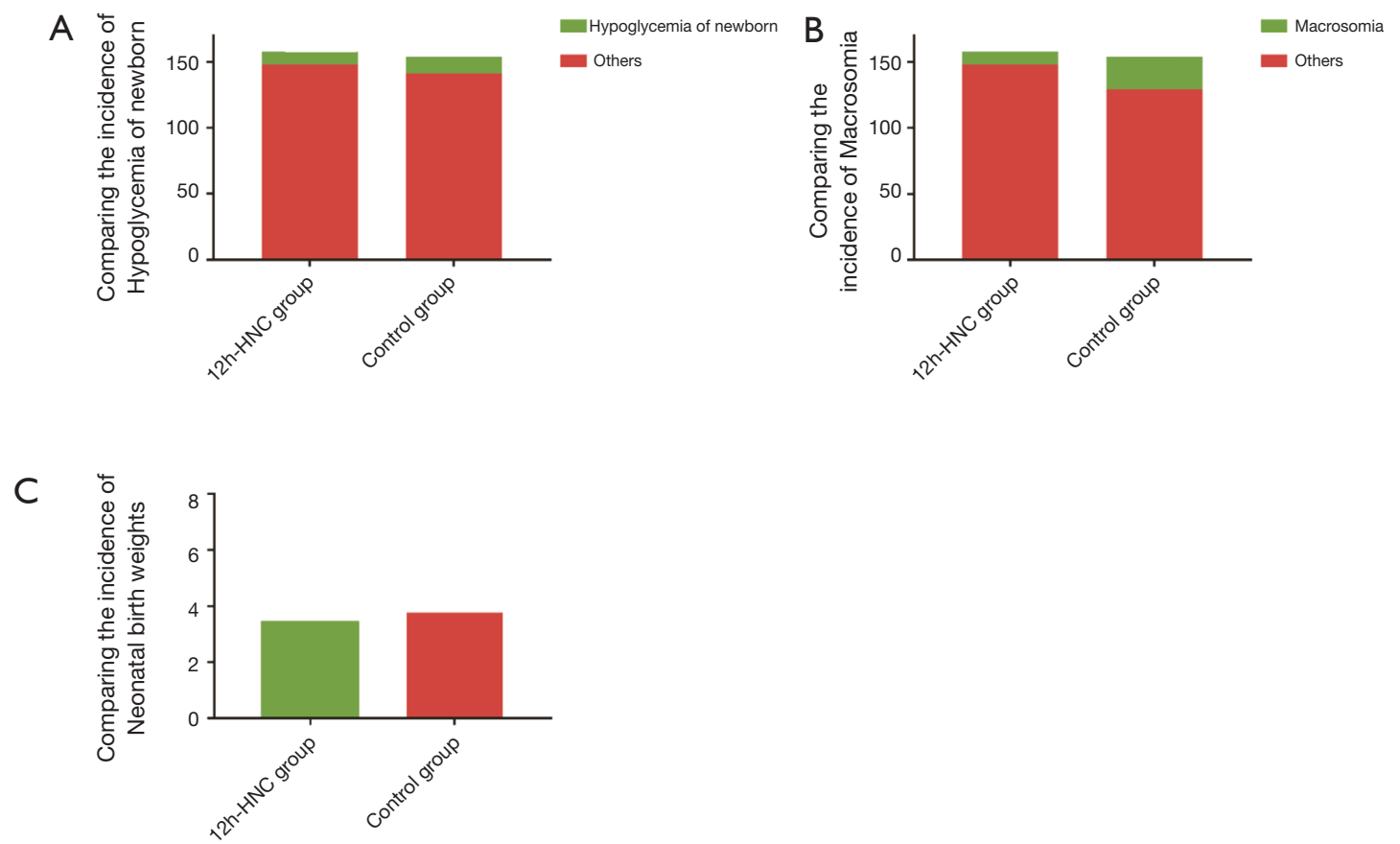

Figure 6 Neonatal outcome comparison. The intervention group had healthier neonates, with a lower incidence of (A) hypoglycemia of newborn and (B) macrosomia, and lower (C) neonatal birth weights. 
of cesarean section among Chinese women. Spontaneous delivery in patients with GDM may result in unexpected adverse events, such as premature rupture of membranes, dystocia, and even death. In contrast, cesarean section provides more safety, less pain, and healthier babies. Therefore, an overwhelming number of patients prefer cesarean section, even in the absence of corresponding indications. This may have led to the different results in our study.

\section{Conclusions}

The $12 \mathrm{~h}-\mathrm{HNC}$ enabled better control of blood glucose levels and lower average weight increase after a trial on 300 patients with GDM. Therefore, this comprehensive intervention has broad prospects for future use to reduce complications and improve the maternal and neonatal outcomes in pregnant women with GDM.

\section{Acknowledgments}

Funding: None.

\section{Footnote}

Conflicts of Interest: All authors have completed the ICMJE uniform disclosure form (available at http://dx.doi. org/10.21037/apm.2020.03.16). The authors have no conflicts of interest to declare.

Ethical Statement: The authors are accountable for all aspects of the work in ensuring that questions related to the accuracy or integrity of any part of the work are appropriately investigated and resolved. This study complied with the Declaration of Helsinki and was approved by Ethics Committees of the Fourth Hospital of Shijiazhuang (No. 20200001). All patients provided written informed consent.

Open Access Statement: This is an Open Access article distributed in accordance with the Creative Commons Attribution-NonCommercial-NoDerivs 4.0 International License (CC BY-NC-ND 4.0), which permits the noncommercial replication and distribution of the article with the strict proviso that no changes or edits are made and the original work is properly cited (including links to both the formal publication through the relevant DOI and the license). See: https://creativecommons.org/licenses/by-nc$\mathrm{nd} / 4.0 /$.

\section{References}

1. Weijers RN, Bekedam DJ, Smulders YM. Determinants of mild gestational hyperglycemia and gestational diabetes mellitus in a large dutch multiethnic cohort. Diabetes Care 2002;25:72-7.

2. Ben-Haroush A, Yogev Y, Hod M. Epidemiology of gestational diabetes mellitus and its association with Type 2 diabetes. Diabet Med 2004;21:103-13.

3. Hu ZG, Tan RS, Jin D, et al. A low glycemic index staple diet reduces postprandial glucose values in Asian women with gestational diabetes mellitus. J Investig Med 2014;62:975-9.

4. Agarwal MM, Punnose J, Dhatt GS. Gestational diabetes: implications of variation in post-partum follow-up criteria. Eur J Obstet Gynecol Reprod Biol 2004;113:149-53.

5. Lowe WL Jr, Scholtens DM, Kuang A, et al. Hyperglycemia and Adverse Pregnancy Outcome Followup Study (HAPO FUS): Maternal Gestational Diabetes Mellitus and Childhood Glucose Metabolism. Diabetes Care 2019;42:372-80.

6. Metzger BE, Lowe LP, Dyer AR, et al. Hyperglycemia and adverse pregnancy outcomes. $\mathrm{N}$ Engl J Med 2008;358:1991-2002.

7. Sesmilo G, Meler E, Perea V, et al. Maternal fasting glycemia and adverse pregnancy outcomes in a Mediterranean population. Acta Diabetol 2017;54:293-9.

8. Sweeting AN, Ross GP, Hyett J, et al. Gestational Diabetes Mellitus in Early Pregnancy: Evidence for Poor Pregnancy Outcomes Despite Treatment. Diabetes Care 2016;39:75-81.

9. Grieger JA, Bianco-Miotto T, Grzeskowiak LE, et al. Metabolic syndrome in pregnancy and risk for adverse pregnancy outcomes: A prospective cohort of nulliparous women. PLoS Med 2018;15:e1002710.

10. Wu P, Farrell WE, Haworth KE, et al. Maternal genomewide DNA methylation profiling in gestational diabetes shows distinctive disease-associated changes relative to matched healthy pregnancies. Epigenetics 2018;13:122-8.

11. Kjos SL, Buchanan TA, Greenspoon JS, et al. Gestational diabetes mellitus: the prevalence of glucose intolerance and diabetes mellitus in the first two months post partum. Am J Obstet Gynecol 1990;163:93-8.

12. Buchanan TA, Xiang A, Kjos SL, et al. What is gestational diabetes. Diabetes Care 2007;30:S105-11. 
13. Bao W, Tobias DK, Bowers K, et al. Physical activity and sedentary behaviors associated with risk of progression from gestational diabetes mellitus to type 2 diabetes mellitus: a prospective cohort study. JAMA Intern Med 2014; 174:1047-55.

14. Gunderson EP, Hurston SR, Ning X, et al. Lactation and Progression to Type 2 Diabetes Mellitus After Gestational Diabetes Mellitus: A Prospective Cohort Study. Ann Intern Med 2015;163:889-98.

15. Geach T. Diabetes: A metabolomic signature to predict the transition from GDM to T2DM. Nat Rev Endocrinol 2016;12:498.

16. Hanna FW, Peters JR. Screening for gestational diabetes; past, present and future. Diabet Med 2002;19:351-8.

17. Kim C, Newton KM, Knopp RH. Gestational diabetes and the incidence of type 2 diabetes: a systematic review. Diabetes Care 2002;25:1862-8.

18. Davies MJ, D'Alessio DA, Fradkin J, et al. Management of Hyperglycemia in Type 2 Diabetes, 2018. A Consensus Report by the American Diabetes Association (ADA) and the European Association for the Study of Diabetes (EASD). Diabetes Care 2018;41:2669-701.

19. Smith BJ, Cinnadaio N, Cheung NW, et al. Investigation of a lifestyle change strategy for high-risk women with a history of gestational diabetes. Diabetes Res Clin Pract 2014;106:e60-3.

20. Zhu LB, Cao MM, Wang J, et al. Role of autophagy in LPS-induced inflammation in INS1 cells. Mol Med Rep 2019;19:5211-8.

21. González-Quintero VH, Istwan NB, Rhea DJ, et al. The impact of glycemic control on neonatal outcome in

Cite this article as: Yuan K, Wang H, Chen Y, Li S, Wang Q, Cao Y, Gao S, Xu X, Xie Q. A 12-hour comprehensive nutrition care benefits blood glucose level and weight gain and improves outcomes in pregnant women with gestational diabetes mellitus. Ann Palliat Med 2020;9(3):661-670. doi: 10.21037/apm.2020.03.16 singleton pregnancies complicated by gestational diabetes. Diabetes Care 2007;30:467-70.

22. Agha-Jaffar R, Oliver N, Johnston D, et al. Gestational diabetes mellitus: does an effective prevention strategy exist. Nat Rev Endocrinol 2016;12:533-46.

23. Mackillop L, Hirst JE, Bartlett KJ, et al. Comparing the Efficacy of a Mobile Phone-Based Blood Glucose Management System With Standard Clinic Care in Women With Gestational Diabetes: Randomized Controlled Trial. JMIR Mhealth Uhealth 2018;6:e71.

24. Liu Z, Ao D, Yang H, et al. Gestational weight gain and risk of gestational diabetes mellitus among Chinese women. Chin Med J (Engl) 2014;127:1255-60.

25. Logan KM, Emsley RJ, Jeffries S, et al. Development of Early Adiposity in Infants of Mothers With Gestational Diabetes Mellitus. Diabetes Care 2016;39:1045-51.

26. Black MH, Sacks DA, Xiang AH, et al. The relative contribution of prepregnancy overweight and obesity, gestational weight gain, and IADPSG-defined gestational diabetes mellitus to fetal overgrowth. Diabetes Care 2013;36:56-62.

27. Tieu J, McPhee AJ, Crowther CA, et al. Screening for gestational diabetes mellitus based on different risk profiles and settings for improving maternal and infant health. Cochrane Database Syst Rev 2017;8:CD007222.

28. Gomes D, von Kries R, Delius M, et al. Late-pregnancy dysglycemia in obese pregnancies after negative testing for gestational diabetes and risk of future childhood overweight: An interim analysis from a longitudinal mother-child cohort study. PLoS Med 2018;15:e1002681. 